\title{
Aurelia Castillo de González
}

1842-1942

$\mathbf{L}$

A literatura cubána inició su existencia siendo tomántica, y aún hoy conserva reflejos o supervivencias de aquella nota de origen. A mediados del siglo XIX, todo escritor venía a la vida literaria en un ambiente saturado de ramanticismo: romanticismo ideológico y político, lo mismo que propiamente literario. La pléyade de escritoras cubanas que enriquecieron nuestras letras por aquellos tiempos, se caracterizaron por la emotividad romántica, tanto por razones atribuíbles a la personalidad femenina, como por motivos de orden histórico. Un caso entre ellos fué el de Aurelia Castillo de González, poetisa y prosista de abundante y variada producción, de forma espontánea, fácil, a veces de transparencia clásica y de espíritu delicadamente romántico; pero su caso es también el de una acentuada y amable personalidad. A cien años de distancia, reconstruimos históricamente el círculo cerrado de la vida provinciana de Camagüey, que sirvió de marco a la existencia juvenil de figuras eminentes o notables como Varona, el Lugareño, Borrero o Aurelia Castillo, y de tales evocaciones tiene que salir vigorizado el concepto exaltador de la personalidad humana. En circunstancias como aquéllas, el individuo se sobrepone al medio, $y$ en cierta medida, de una manera o de otra, lo domina, lo conquista, y lógicamente vale más que él. La vida y la obra de Aurelia Castillo es un reiterado esfuèrzo de superación de las circunstancias, una lección ejemplar de autoformación espiritual, de progreso pausado y firme en la adquisición y dominio de un estilo artístico. 
La autora emplea con igual facilidad la prosa o el verso. Realmente no prefiere una $\mathrm{u}$ otra forma de expresión artística, como que en ambas encontró apropiado cauce para la manifestación cle su vida interior, que fué la gran finalidad, el motivo a un tiempo íntimo y superficial de su actividad literaria. Ejemplo de artista a la vez temperamental y laborioso, cultivó el verso lírico y el descriptivo, la fábula y la leyenda, la crónica literaria - que es con frecuencia crítica inspirada en un impresionismo optimista y generoso-, el libro de viajes, el periodismo y la biografía. Toda esta extensa producción se halla matizada por un suave y diluído espiritualismo, y animada por el amor a la tierra nativa y por el culto a las virtudes hogareñas.

Lo cotidiano y familiar se torna poético en lós versos de Aurelia Castillo, merced a la ingenuidad y espontánea sencillez de su canto. Por eso pudo ella convertir en materia artística recuerdos de su primer hogar, sucesos y personajes de la quieta vida principeña, tradiciones y cosas de la tierra querida, poetizar el agua de tinajón, convirtiéndola en intima emoción del terruño, en cosa cantable; fijar con arte y naturalidad, para satisfacción de otros, la impresión personal de viajes por Europa y América, y en fin, actualizar para la posteridad, a través del verso o del relato en prosa, escenas e impresiones pasajeras de la vida doméstica, sucesos de la vulgar existencia diaria.

Su obra ofrece un sencillo conjunto de líneas armoniosas, y debe ser juzgada en su realización integral, no en sus detalles o en aspectos aislados. Apreciada sin criterio histórico muy firme, pudiera parecer artísticamente muy lejana de nuestra época, en absoluta oposición con los gustos literarios de los t́ltimos tiempos; pero de su producción abundante perduran, como elementos particularmente dignos de recuerdo, la simplicidad emotiva, la delicadeza, la nobleza de arte y de pensamiento, y una como suave fragancia que es la poética concreción de su personalidad. Su poesía es poesía personal, llevada por un impulso romántico peculiar, propio, a través de escuelas y tendencias literarias, alejada de todas, hacia un ideal de perfeccionamiento de la forma y de refinamiento interior. Su prosa muestra los earacteres de una evolución pausada y firme. Después de persistente ejercicio, su pluma adquiere agilidad y destreza. La autora de las Leyendas americanas, de la cálida biografía de Ignacio Agramonte y de tantas crónicas, cartas y relatos interesantes, 
describe animadamente, sin esfuerzo, narra con amenidad, y es siempre la escritora que conoce su noble oficio literario y lo ejerce sin fatiga, asistida por un generoso entusiasmo que conserva hasta sus últimos años. Si su obra poética fué la base de su popularidad, su prosa, en conjunto, presenta caracteres de una evolución artística 'superior, y le asegura más justificada perdurabilidad a su nombre.

Camagüey, que fué su gran emoción humana y su gran tema literario, al rendir homenaje a Aurelia Castillo de González, con motivo del centenario de su nacimiento, ha realizado un acto de justicia histórica al par que una loable afirmación de valores literarios que, sin perjuicio de su trascendencia, se destacan por su plácido y fervoroso regionalismo. Si la personalidad de la autora conmemorada no adquiere la magnitud artística ni el perfil extraordinario de pasional humanidad de Gertrudis Gómez de Avellaneda, ni la trascendencia y el refinamiento de la de Varona, su obra, por la persistencia del noble esfuerzo que revela, por su dulce y no aprendido nativismo, por la armonía y suavidad de líneas del conjunto, $\mathrm{y}$ por una rara $\mathrm{y}$ feliz combinación de feminismo y de feminidad, es un preciado aporte de Camagüey a la historia literaria cubana, y por él, el nombre de Aurelia Castillo se incorpora, en honrosa asociación, a los de aquellos hijos ilustres que hicieron de su tierra, además de patria de heroísmos, tierra esclarecida por obras perdurables del pensamiento y del arte.

Raimundo Lazo, Universidad de La Habana. 
